\title{
Retrieving hurricane wind speeds using cross-polarization C-band measurements
}

\author{
G.-J. van Zadelhoff ${ }^{1}$, A. Stoffelen ${ }^{1}$, P. W. Vachon ${ }^{2}$, J. Wolfe ${ }^{2}$, J. Horstmann ${ }^{3,4}$, and M. Belmonte Rivas ${ }^{5}$ \\ ${ }^{1}$ Royal Netherlands Meteorological Institute, De Bilt, the Netherlands \\ ${ }^{2}$ Defence R\&D Canada, Ottawa, Ontario, Canada \\ ${ }^{3}$ Center for Maritime Research and Experimentation, La Spezia, Italy \\ ${ }^{4}$ Institute of Coastal Research, Helmholtz-Zentrum Geesthacht, Geesthacht, Germany \\ ${ }^{5}$ Geoscience and Remote sensing, Technical University Delft, Delft, the Netherlands
}

Correspondence to: G.-J. van Zadelhoff (zadelhof@knmi.nl)

Received: 22 May 2013 - Published in Atmos. Meas. Tech. Discuss.: 28 August 2013

Revised: 18 December 2013 - Accepted: 2 January 2014 - Published: 7 February 2014

\begin{abstract}
Hurricane-force wind speeds can have a large societal impact and in this paper microwave C-band crosspolarized $(\mathrm{VH})$ signals are investigated to assess if they can be used to derive extreme wind-speed conditions. European satellite scatterometers have excellent hurricane penetration capability at C-band, but the vertically (VV) polarized signals become insensitive above $25 \mathrm{~m} \mathrm{~s}^{-1}$. VV and $\mathrm{VH}$ polarized backscatter signals from RADARSAT-2 SAR imagery acquired during severe hurricane events were compared to collocated SFMR wind measurements acquired by NOAA's hurricane-hunter aircraft. From this data set a geophysical model function (GMF) at strong-to-extreme/severe wind speeds (i.e., $20 \mathrm{~m} \mathrm{~s}^{-1}<U_{10}<45 \mathrm{~m} \mathrm{~s}^{-1}$ ) is derived. Within this wind speed regime, cross-polarized data showed no distinguishable loss of sensitivity and as such, cross-polarized data can be considered a good candidate for the retrieval of strong-to-severe wind speeds from satellite instruments. The upper limit of $45 \mathrm{~m} \mathrm{~s}^{-1}$ is defined by the currently available collocated data. The validity of the derived relationship between wind speed and VH backscatter has been evaluated by comparing the cross-polarized signals to two independent wind-speed data sets (i.e., short-range ECMWF numerical weather prediction (NWP) model forecast winds and the NOAA best estimate 1-minute maximum sustained winds). Analysis of the three comparison data sets confirm that cross-polarized signals from satellites will enable the retrieval of strong-to-severe wind speeds where $\mathrm{VV}$ or horizontal $(\mathrm{HH})$ polarization data has saturated. The VH backscatter increases exponentially with respect to wind speed (linear
\end{abstract}

against $\mathrm{VH}[\mathrm{dB}]$ ) and a near-real-time assessment of maximum sustained wind speed is possible using $\mathrm{VH}$ measurements. VH measurements thus would be an extremely valuable complement on next-generation scatterometers for hurricane forecast warnings and hurricane model initialization.

\section{Introduction}

Wind speeds and/or directions over oceans are routinely measured with high spatial and temporal resolution by active radar instruments such as scatterometers and synthetic aperture radars (SARs). The winds can be inferred from the measured normalized radar cross section (NRCS) signal strength (sigma 0 or $\sigma_{0}$ ) as these are linked to the ocean roughness and its azimuthal variation, even though the exact mechanisms behind this are still not fully understood theoretically (e.g., Romeiser et al., 1997).

In the case of scatterometers, the wind speed and direction can be retrieved using three collocated measurements from different azimuth viewing angles combined with the geophysical C-band model (CMOD) function that empirically links the radar backscatter to the local wind vector and incidence angle (e.g., Stoffelen and Portabella, 2006). In the case of SAR instruments, additional wind-direction information is required to determine the absolute wind speed, using copolarization (vertically transmitted and vertically polarized, VV or its horizontal equivalent, $\mathrm{HH}$ ) signals. 
Near-real-time global wind estimates from various scatterometer instruments provide spatial resolutions on the order of tens of kilometers and are proven to be very accurate (Vogelzang et al., 2011). Scatterometers are used in diverse applications including marine meteorology, Numerical Weather Prediction (NWP), oceanography and climate (Bourassa et al., 2009; Vogelzang and Stoffelen, 2012). The high spatial resolution (about a $100 \mathrm{~m}$ ) provided by SAR instruments, can be used to determine local wind-speed phenomena in bays, fjords and along the coast line provided the prevailing wind direction is uniform (Portabella et al., 2002). Besides their limited coverage, another main limitation of SAR systems is their calibration stability. Scatterometers generally achieve a much better calibration stability than SARs. A main limitation of the ASCAT fan-beam scatterometer is the low sensitivity of co-polar signal strength with respect to severe wind speeds $\left(>25 \mathrm{~m} \mathrm{~s}^{-1}\right)$. This reduces the ability to derive wind speeds during severe wind events like hurricanes and typhoons. In recent years, RADARSAT2 cross-polarization signals $(\mathrm{VH})$ have been studied in more detail, and a rather simple and useful relationship to the severe wind speed has emerged. The operational use of crosspolarization signals for wind retrievals over the ocean will only be possible in future meteorological satellite systems.

The Meteorological Operational satellite programme Second Generation (MetOp-SG) satellites will replace the current MetOp system in the 2020+ time frame. One instrument to be carried on board the MetOP-SG is a C-band scatterometer (SCA), similar to ASCAT on MetOp, but with higher spatial resolution, increased coverage and stability. The prime objective of SCA, herein referred to as ASCAT-SG, will be to measure wind speed and direction over the oceans, following its predecessor ASCAT on MetOp. Another innovation in the design of ASCAT-SG is the inclusion of a single cross-polarization beam, which can be used for the retrieval of severe wind speeds and therefore be a prime improvement in the nowcasting of hurricane intensities, for the protection of coastal residents and infrastructure. This combination of three VV with one VH channel improves the extreme wind retrieval without degrading the low wind-speed determination (Belmonte Rivas et al., 2013).

In preparation for ASCAT-SG, the cross-polarization (VH) data from the RADARSAT-2 satellite are compared to wind speeds (Sect. 2) measured by NOAA's hurricane hunter flights (Sect. 2.2) and to wind speeds provided by ECMWF forecasts (Sect. 2.4). The results indicate that VH backscatter is capable of retrieving strong to extreme/severe wind speeds with a weak dependence on wind direction, if any. As such, VH backscatter can be used to complement the standard VV products by extending wind-speed retrieval beyond $25 \mathrm{~m} \mathrm{~s}^{-1}$. In Sect. 3, a new VH geophysical model function is described and used to retrieve the wind speeds in Hurricane Earl (2010). Section 4 describes the use of RADARSAT2 data to nowcast the hurricane best track estimate, as defined by NOAA, thereby showing how cross-polarization measurements can be exploited to warn people about severe wind events. Finally, Sect. 5 provides the main conclusions of this work.

\section{Cross-polarization wind-speed relationships}

\subsection{Low-to-strong wind-speed measurements using buoys and RADARSAT-2}

In the last few years, a number of papers (e.g., Zhang et al., 2011; Zhang and Perrie, 2011; Hwang et al., 2010a; Vachon and Wolfe, 2011; Horstmann et al., 2013) on using the cross-polarized ( $\mathrm{VH}$ or $\mathrm{HV}$ ) synthetic aperture radar (SAR) imagery for the retrieval of wind speeds have been published. These papers are based on data measured by the RADARSAT-2 satellite, which was launched in December 2007 for the Canadian Space Agency. RADARSAT-2 deploys a C-band SAR which can be configured in multiple polarization modes, including a fully polarimetric mode in which $\mathrm{HH}, \mathrm{HV}, \mathrm{VV}$ and $\mathrm{VH}$ polarized data and phase information can be acquired (Slade, 2011). This fine-quad polarization mode has an extremely low noise floor and cross-talk correction between the different channels. The RADARSAT2 mode with the widest swath (ScanSAR Wide A (SCWA)) has a nominal width of $500 \mathrm{~km}$ with a spatial resolution of $100 \mathrm{~m}$, which is spatially averaged to $3 \mathrm{~km}$ resolution. SCWA operates in dual-polarization receive mode (VV and $\mathrm{VH}$, or $\mathrm{HH}$ and $\mathrm{HV}$ ), and shows a significantly higher noise floor $(>-30 \mathrm{~dB})$ when compared to the fine-quad polarization mode.

In the low-to-strong wind-speed regime $\left(\leq 20 \mathrm{~m} \mathrm{~s}^{-1}\right)$ the cross-polarized backscatter by RADARSAT-2 fine quadpolarization $(\mathrm{HH}, \mathrm{HV}, \mathrm{VH}$, and $\mathrm{VV}$ ) mode (see above mentioned papers) has been compared to wind vectors measured at buoys. It was found that the cross-polarized backscatter in $\mathrm{dB}$ was insensitive to incidence angle and wind direction resulting in a simple linear geophysical relationships that may be directly used to derive absolute wind speeds. In contrast to this, the VV backscatter shows a strong incidence angle and azimuthal wind-direction dependence. This VV dependence complicates the retrieval of wind speeds considerably but does enable the retrieval of wind direction (Wackerman et al., 1996; Portabella et al., 2002; Horstmann and Koch, 2005; Stoffelen and Portabella, 2006), which does not seem to be possible for the $\mathrm{VH}$ channel. The absolute wind-speed relationships in the low-to-strong wind-speed regime based on cross-polarization data resulted in very similar results by both Vachon and Wolfe (2011) and Zhang and Perrie (2011):

$$
\mathrm{VH}[\mathrm{dB}]=0.592 \cdot U_{10}\left[\mathrm{~m} \mathrm{~s}^{-1}\right]-35.6
$$

(Vachon and Wolfe, 2011)

$\mathrm{VH}[\mathrm{dB}]=0.580 \cdot U_{10}\left[\mathrm{~m} \mathrm{~s}^{-1}\right]-35.652$

(Zhang and Perrie, 2011). 
Their results showed the potential of a robust wind-speed retrieval method based on the cross-polarization signals alone for hurricane wind speeds.

The results in both Zhang et al. (2011) and Hwang et al. (2010a), where RADARSAT-2 (SCWA) images of hurricanes were used in combination with $\mathrm{VV}$-wind retrievals and NWP model winds, showed that the VH [dB]-wind relationship for strong-to-severe wind speeds follow a different slope compared to that found in Eqs. (1) and (2). These evaluations were performed however with a very limited hurricane data set. The derivation of a statistical VH relationship for strongto-severe $\left(>20 \mathrm{~m} \mathrm{~s}^{-1}\right)$ wind speeds based on a large number of hurricane data is one of the main objectives of this work.

In this work, all presented wind-speed fits are related to $\mathrm{VH}$ measurements in $\mathrm{dB}$, resulting in the wind-speed relationships being described as linear with respect to $\mathrm{VH}[\mathrm{dB}]$. Note that this means that the VH measurements themselves increase exponentially with respect to wind speed.

\subsection{Strong-to-severe wind-speed measurements over hurricanes using NOAA hurricane hunter winds and RADARSAT-2 $\sigma_{0}$}

A total of 19 RADARSAT-2 dual polarized SAR images (VV and $\mathrm{VH}$ ) were acquired, through the Canadian Space Agency's Hurricane Watch program, during strong-to-severe wind events between 2008 and 2011. Hurricane transects and hurricane surface winds were also obtained from the NOAA WP-3D research aircraft carrying the airborne SteppedFrequency Microwave Radiometer (SFMR) (Uhlhorn et al., 2007) instrument. The retrieval of wind speed is based on nadir microwave emissions from the sea surface in $6 \mathrm{C}$-band frequencies along the flight track. The retrieval algorithm is validated using global positioning system (GPS) dropwindsonde measurements and has been shown to retrieve wind speeds within $4 \mathrm{~m} \mathrm{~s}^{-1}$ RMS error from 10 to about $70 \mathrm{~m} \mathrm{~s}^{-1}$. As the SFMR measures the wind speed below the aircraft, the data provides transects/tracks of the wind speeds through the individual hurricanes and not the full wind-speed pattern throughout the hurricane system. The NOAA hurricane hunters flew a total of 18 collocated flight tracks through 9 of the 19 available hurricanes with the SFMR instrument. In Table 1, the hurricane images used in this study are indicated with the dates and times of RADARSAT- 2 overpasses including the number of collocated flight tracks performed within the RADARSAT-2 images which were close enough in space and time to be representative (see below). Figure 1, shows a ScanSAR Wide-A (SCWA) RADARSAT-2 image (converted to $\sigma_{0}$ in $\mathrm{dB}$ ) of Hurricane Earl as observed on 2 September 2010 with the SAR configured in dual-pol mode with VV (bottom panel) and VH (top panel). The VV $\sigma_{0}$ is observed (and expected) to decrease with increasing incidence angle (i.e., from left-to-right in the image), whereas the VH $\sigma_{0}$ does not appear to have any dependence with increasing incidence angle. This is also apparent in the well-defined

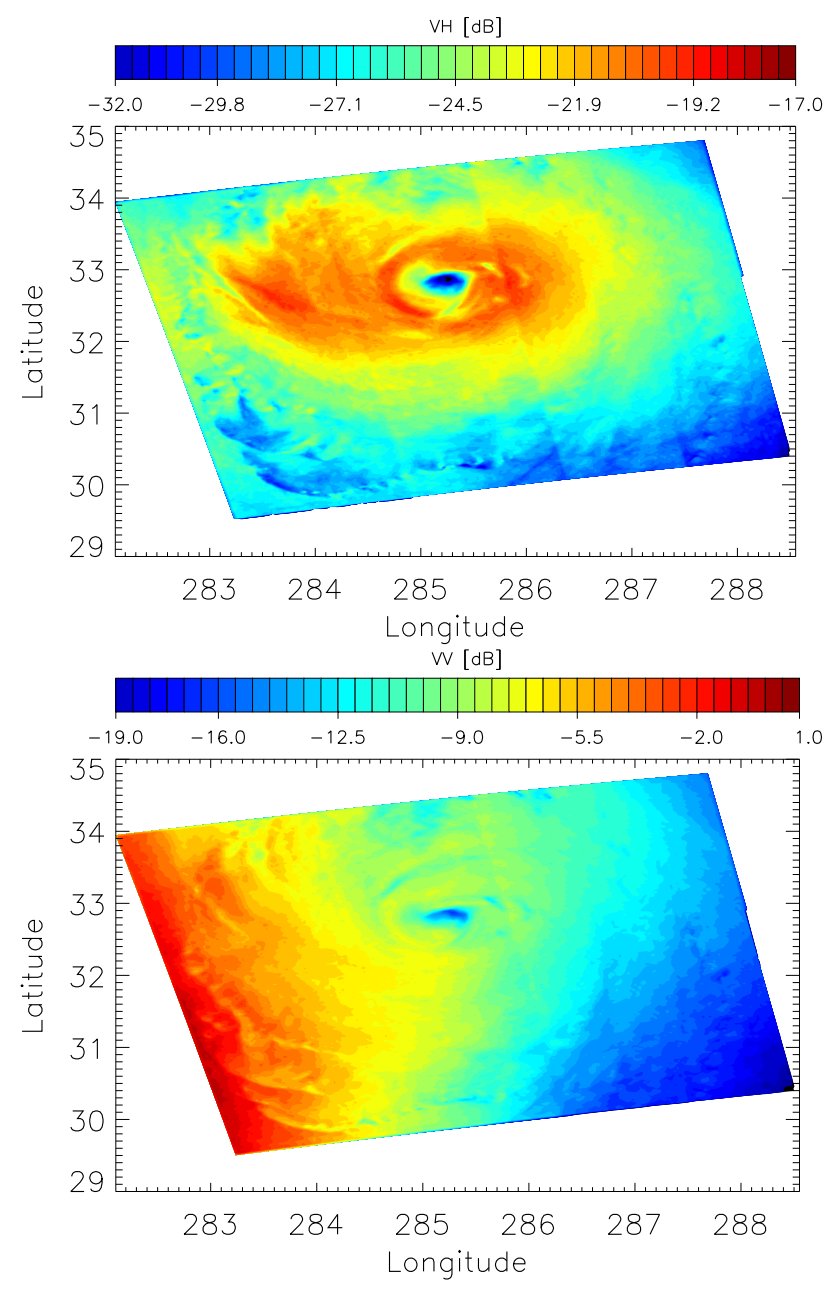

Fig. 1. VH (top) and VV (bottom) $\sigma_{0}$ measurements for Hurricane Earl (2 September 2010). The hurricane wind-speed structure in the $\mathrm{VV}$ band is not clearly visible due to the incidence and azimuthal angle dependencies. The hurricane structure shows a well-defined eye and wind pattern in the $\mathrm{VH}$ band. Note the large difference in signal strength resulting in signals close to the noise level of the instrument.

eye of the hurricane in the $\mathrm{VH}$ image in comparison to the one in the VV image. At low incidence angles the VV-signal saturates close to $0 \mathrm{~dB}$ (left side of the image). The $\mathrm{VH}$ signal strength is lower compared to the co-polarized VV signals. The full image is created by combining 4 individual beams (W1, W2, W3 and S7) to generate SCWA image mode. The four beams are essentially stitched together with a blend operation performed at the beam seams to attempt to mitigate undesirable beam seams. Beam seams can be evident in low signal-to-noise ratio regions as is observed in the VH image as linear features that run over the full along-track extent on either side of the hurricane eye. The beam seams are not as evident in the VV image due to higher signal-to-noise values. The dual polarization data provided by the RADARSAT2 team is a summation of the measured geophysical signal 
Table 1. RADARSAT-2 hurricane images used in this study with acquisition dates and times. The NOAA aircraft made flights through a number of hurricanes for which SFMR wind velocities were measured. The table indicates the number of collocated flight tracks performed within the RADARSAT-2 images which were close enough in time to be representative.

\begin{tabular}{lllc}
\hline Hurricane & Date & Time & SFMR \\
\hline Bertha & 12 Jul 2008 & 10:14:41 & 2 \\
Ike & 4 Sep 2008 & 21:49:28 & - \\
Ike & 10 Sep 2008 & 23:54:57 & - \\
Ike & 10 Sep 2008 & $23: 56: 03$ & - \\
Bill & 22 Aug 2009 & $22: 26: 56$ & 2 \\
Bill & 22 Aug 2009 & $22: 27: 41$ & 2 \\
Bill & 23 Aug 2009 & $10: 40: 57$ & 1 \\
Earl & 30 Aug 2010 & $09: 57: 38$ & 2 \\
Danielle & 30 Aug 2010 & $22: 04: 20$ & 2 \\
Earl & 2 Sep 2010 & $22: 59: 20$ & 4 \\
Igor & 14 Sep 2010 & $09: 19: 42$ & - \\
Adrian & 10 Jun 2011 & $01: 08: 36$ & - \\
Dora & 22 Jul 2011 & $13: 09: 52$ & 2 \\
Eugene & 5 Aug 2011 & $02: 17: 01$ & - \\
Hilary & 29 Sep 2011 & $02: 13: 05$ & 1 \\
Phillipe & 1 Okt 2011 & $21: 25: 04$ & - \\
Jova & 9 Okt 2011 & $13: 07: 24$ & - \\
Irwin & 12 Okt 2011 & $13: 19: 08$ & - \\
Irwin & 12 Okt 2011 & $13: 20: 15$ & - \\
\hline
\end{tabular}

$\left(\sigma_{0}\right)$ and the noise equivalent sigma zero (NESZ). The NESZ is the noise (bias) using the known and modeled properties of the instrument and has a value around $-30 \mathrm{~dB}$, which may vary by $1-2 \mathrm{~dB}$. The local value of the NESZ, which is incidence-angle dependent, is assumed to be correct within $1 \mathrm{~dB}$ (Vachon and Wolfe, 2011). For both the VV and VH signals only those combined signals which were larger than $\mathrm{NESZ}+1 \mathrm{~dB}$ are taken into account within this work, before the NESZ is subtracted from the measured signals to obtain the noise-corrected $\sigma_{0}$. The resulting signals can therefore reach values down to $-35 \mathrm{~dB}$ for those measured values just above $1 \mathrm{~dB}$ of the noise floor.

\subsection{Collocating RADARSAT-2 with NOAA hurricane hunter flights}

The construction of wind speed versus cross-polarization relationships require a validated wind product. For a number of hurricanes there is the availability of hurricane surface winds from the NOAA WP-3D research aircraft (Uhlhorn et al., 2007). A typical NOAA flight takes around $6 \mathrm{~h}$ and within this time a number of flight legs are flown through the eye of the hurricane. Compared to the near-instantaneous measurements of RADARSAT-2, both data streams will never be fully collocated in time and space, especially when taking into account the hurricanes intrinsic movement during the flight. Therefore, each of the individual legs (lasting about
$20 \mathrm{~min}$ ) has to be collocated separately. The number of individual flight legs for each hurricane, in which a NOAA flight was close enough in space and time is presented in Table 1. To determine if a flight leg is a candidate for inclusion in the data set, the time difference between the RADARSAT- 2 and NOAA flight acquisitions is first calculated. If the time difference is $<24 \mathrm{~h}$, the flight is separated in to different flight legs by looking for large changes in flight direction $\left(>90^{\circ}\right)$. Overall most flight legs occur within $3 \mathrm{~h}$ of the RADARSAT-2 acquisition time. Only the Hurricane Bill image acquired on 22 August exceeded the $24 \mathrm{~h}$ maximum (by $3 \mathrm{~h}$ ). Each flight leg is checked for a passage through the center of the hurricane by matching the measured velocity patterns through the hurricane eye with the position of the eye as determined in the RADARSAT-2 image. For those flight legs which contain a hurricane eye, the entire SFMR leg is shifted in longitude and latitude to match the centers, after which the $\mathrm{VH}$ measurements are collocated onto the measured points of the SFMR. Finally, the chosen flight legs with the collocated VH data are checked for large inconsistencies (i.e., did the aircraft clearly pass through a different part of the hurricane). Since the rotation of the hurricane is not taken into account in this procedure, a comparison between the two data sources can only be made statistically. By combining a large number of flight legs with collocated VH data, the collocation errors should increase the width of the distribution without inducing a bias.

In Fig. 2 a comparison of a single flight leg through Hurricane Earl is shown. Plotted are the individual retrieved SFMR wind speed (black line) measurements along the flight track and the collocated RADARSAT-2 measured VH signal (blue line). A clear correlation is visible between the two signals. By combining all the available legs from the nine measured hurricanes the 2-D joint distribution shown in Fig. 3 is created. Due to the high instrument noise floor in the SCWA mode, the lower part of the distribution below $-35 \mathrm{~dB}$ is missing compared to the data used in the Vachon and Wolfe (2011) and Zhang and Perrie (2011) papers, which used the more sensitive (but smaller spatial extent) fine quadpolarization RADARSAT-2 mode. This affects the velocity distribution below $20 \mathrm{~ms}^{-1}$ and only a hint of the fit by Vachon and Wolfe (2011) (Eq. 1; dashed-dotted line) in this velocity regime is visible. Above $20 \mathrm{~m} \mathrm{~s}^{-1}$ a different slope compared to the low wind speed fit is apparent.

The median results for the RADARSAT- 2 collocated ECMWF-fields $^{1}$, the HWIND model $^{2}$ and the retrieved wind from the VV channel using the CMOD5.n geophysical model function (Verhoef, 2008) are overplotted on the distribution. The ECMWF wind fields are obtained from short-range forecasts with 3-hour intermittency. HWIND is a model field which provides an integrated view of the extent and strength of the wind field and is used operationally to improve the

\footnotetext{
${ }^{1}$ http://www.ecmwf.int/products/forecasts/d/charts

${ }^{2}$ http://www.aoml.noaa.gov/hrd/data_sub/wind.html
} 


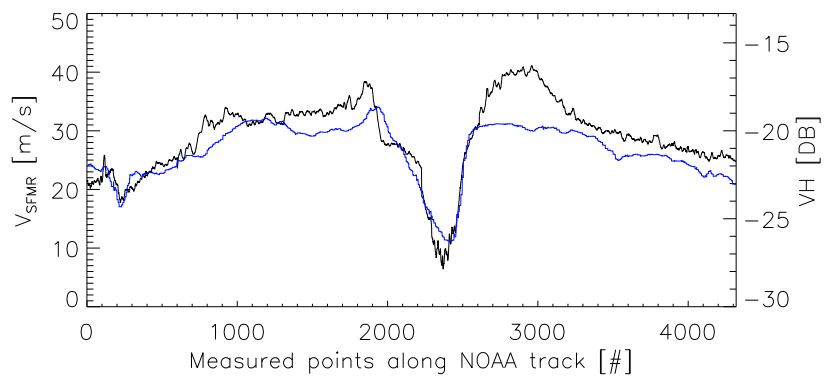

Fig. 2. Retrieved SFMR wind speeds from a flight track through Hurricane Earl (black line). The blue line depicts the collocated VH RADARSAT-2 measurements.

assessment of hurricane intensity (Powell et al., 1998). The computation of the VV-GMF wind speed requires knowledge of the $\operatorname{VV}\left(\sigma_{0}\right)$, incidence angle and wind direction. Since RADARSAT- 2 detects only one azimuth viewing direction the wind retrievals can not be determined independently. Within this study, two different wind-direction descriptions, required for the VV-GMF calculations are used. In the first the forecasted ECMWF wind direction of the $10 \mathrm{~m}$ wind is assumed, secondly the assumption that the wind rotates perfectly circular around the center of a hurricane. Comparisons showed that there is no significant difference between the $U_{10}\left(\mathrm{VV}, \phi_{\mathrm{ECMWF}}\right)$ and $U_{10}\left(\mathrm{VV}, \phi_{\text {rotate }}\right)$ versus $\mathrm{VH}[\mathrm{dB}]$ distributions. A third method to determine wind direction, by using surface features (Lehner et al., 1998; Horstmann and Koch, 2005), has not been adopted in this work.

The ECMWF and HWIND models, VV-GMF and the median SFMR measurements show a similar change in slope for severe wind speeds $\left(>20 \mathrm{~m} \mathrm{~s}^{-1}\right)$. The SFMR measurements are between 1 and $3 \mathrm{~dB}$ lower than the VV-GMF as the wind speed increases from 20 to $40 \mathrm{~m} \mathrm{~s}^{-1}$, respectively. Furthermore, below $20 \mathrm{~m} \mathrm{~s}^{-1}$, the slope for both the VV-GMF and the median SFMR measurements are similar to the Vachon and Wolfe (2011) relationship. The VV-GMF median fit depicts the highest slope, which indicates its lack of sensitivity for extreme wind retrievals. The collocated ECMWF forecast data has a similar slope up to $20 \mathrm{~m} \mathrm{~s}^{-1}$ but shows a lower sensitivity in the extreme wind regime. This is most likely due to the lower spatial resolution in the model, thereby smoothing the largest gradients close to the outer eye wall (no ECMWF winds within the eye wall were used). The HWIND model shows a larger wind speed at all collocated VH measurement from 10 to $45 \mathrm{~m} \mathrm{~s}^{-1}$. The exact transition from strong to severe wind speeds (i.e., the transition from the Vachon and Wolfe (2011) relationship to the severe wind-speed regime), can not be assessed at this point based on these data only. The SFMR distribution is well defined up to $40 \mathrm{~m} \mathrm{~s}^{-1}$ with a correlation of 0.70 and can be related to $\mathrm{VH}$ in between 21 and $40 \mathrm{~m} \mathrm{~s}^{-1}$ as

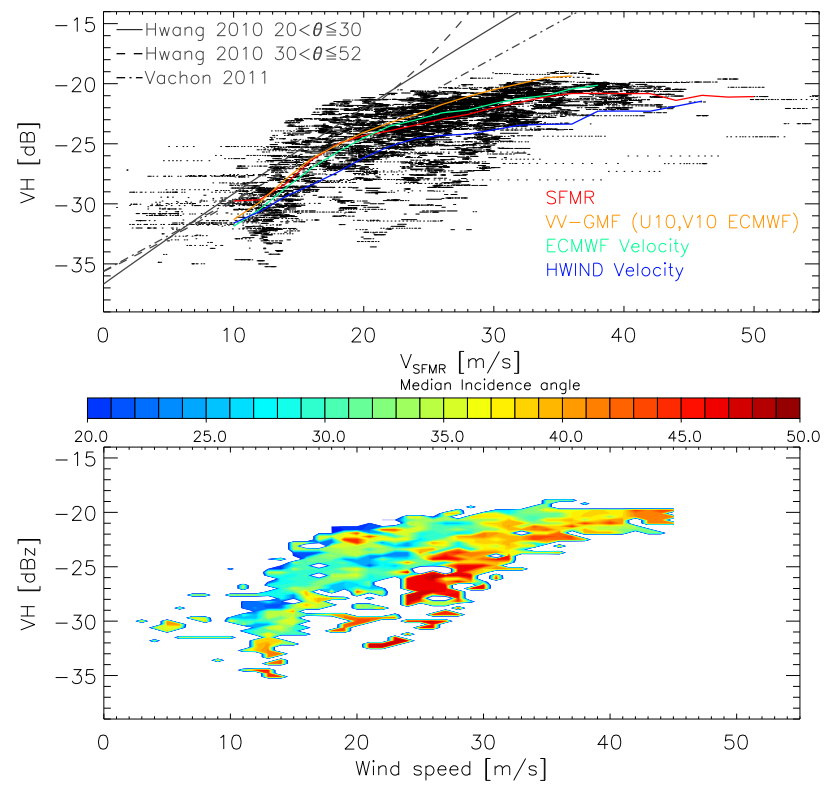

Fig. 3. Distribution of all retrieved SFMR wind speeds versus collocated VH measurement points from nine hurricanes (top panel). The red line shows the median backscatter within $2 \mathrm{~ms}^{-1}$ velocity bins for the distribution. Overlaid are the median values for the distributions of the VH measurements with collocated ECMWF and HWIND models and the wind velocity retrievals from the VV-band, respectively. The black lines show different results from literature. In the bottom panel, the distribution of the median incidence angles, within $2 \mathrm{~ms}^{-1}$ by $2 \mathrm{~dB}$ bins, depicting a possible incidence-angle dependence within the distribution.

$\mathrm{VH}\left(21<U_{10}<40 \mathrm{~m} \mathrm{~s}^{-1}\right)=0.218 U_{10}-29.07$

Theoretical derivations by Hwang et al. (2010b) and Voronovich and Zavorotny (2011), showed that the crosspolarization signals should depict an incidence-angle dependence. This was also indicated by measurements using a limited set of the RADARSAT-2 SCWA data (Hwang et al., 2010a). The high signal-to-noise measurements from the fine-quad polarization mode, however, showed a lack of apparent incidence-angle dependence (Vachon and Wolfe, 2011; Zhang and Perrie, 2011). In Fig. 3, the 2-D histogram of median incidence angle is plotted in the bottom panel. There seems to be a shift in parameter space between small incidence angle (top left of the distribution) and large incidence angle (bottom right); however, not enough independent data is available from the SFMR data to determine any underlying incidence-angle dependence directly. In the next section, the incidence-angle dependence is analyzed in more detail by comparing the $\mathrm{VH}$ data to the ECMWF wind velocity forecasts. 


\subsection{Incidence and azimuthal angle dependence using ECMWF forecasts}

An independent method to assess the incidence-angle and wind-direction dependencies is performed by comparing the VH measurements to the NWP model calculations or wind retrievals from the VV-band. By incorporating all individual $\mathrm{VH}$ pixels for the 19 hurricane images enough data is acquired to retrieve these dependencies statistically. Both comparisons have their pros and cons. The VV wind-speed retrievals are perfectly collocated to the VH observations but have sensitivity issues when retrieving extreme wind speeds beyond $25 \mathrm{~m} \mathrm{~s}^{-1}$. On the other hand, one could use forecasts from an NWP model at all speeds. However, a global NWP model, in this case the ECMWF model, has a lower resolution and is not collocated in space and time. The lower resolution will result in a smoothed wind field, potentially missing small regions with high wind speeds or high wind shear. The ECMWF model is known to provide good forecasts in the case of tropical hurricanes; therefore, it is expected that the model will provide a good statistical description of the general wind field except close to the hurricane eye where the spatial variability is largest.

In this work, the ECMWF model comparison was preferred to the VV retrieved wind speeds because the VV retrieved wind speed depends on both the incidence and azimuth angles. If these dependencies are not perfectly defined in the geophysical model function (VV-GMF), then any offset will feed into a newly developed VH-GMF parameterization. In contrast, the ECMWF model is independent of the RADARSAT-2 geometry and therefore, distributions of collocated data should not produce a bias in any potential azimuthal or incidence-angle dependence. The ECMWF wind speeds may, however, underestimate the maximum sustained winds as measured by RADARSAT- 2 .

For all the hurricanes, the ECMWF forecast was retrieved on a $0.25^{\circ} \times 0.25^{\circ}$ grid. Since the ECMWF provides 3-hour outputs, the closest time slot to the RADARSAT-2 image overpass was used. This results in a small offset in collocation which has to be corrected for. The correction offset method was preferable to interpolating the ECMWF fields to the correct time which induced stretching of the hurricane shape. For each of the ECMWF fields, the center of the hurricane was determined by looking for the hurricane eye in the modeled velocity, after which, the ECMWF field was translated to match the VH hurricane center. The ECMWF field was subsequently bi-linearly interpolated (up-scaled) to the RADARSAT- 2 resolution. Since the ECMWF resolution is lower, compared to the RADARSAT- 2 data, it will miss the high variations in wind speed close to the hurricane eye. To reduce the amount of potential missing features, the radius of maximum wind speed ( $\left.R_{\text {ecmwf }}\right)$ in the ECMWF wind field is first calculated. All wind velocities within 1.1 times $R_{\text {ecmwf }}$ are removed from the comparison to reduce the regimes for which the ECMWF model will clearly be biased low. This precaution filters out the highest wind velocities from the ECMWF model fields.

In Fig. 4, the number density histogram of the combined hurricane distribution is shown. The individual hurricanes overlap in the same part of parameter space resulting in a tight distribution with a correlation of 0.85 in $U_{10}$ vs. VH [dB]. In the bottom panel, the median incidence angle, binned in wind speed and $\mathrm{VH}$ strength, is plotted showing a very similar incidence dependence as was suggested by the SFMR data (Fig. 3). This could indicate a VH GMF incidence-angle dependency and/or sampling or calibration problem in the RADARSAT- 2 data, either, of which would reduce the correlation in the plots.

\subsubsection{Incidence-angle dependence}

In order to resolve the potential incidence-angle dependence, a number of linear regression lines (Eq. 4) were fitted to the $\mathrm{VH}[\mathrm{dB}]$ measurements versus ECMWF velocity for different incidence-angle bins. The linear fits,

$\operatorname{VH}_{\mathrm{ECMWF}}(\theta)[\mathrm{dB}]=A(\theta)+B(\theta) \cdot U_{10}\left[\mathrm{~m} \mathrm{~s}^{-1}\right]$,

were performed in between 7 and $20 \mathrm{~ms}^{-1}$ and not the entire wind-speed regime. There is a clear regime change at around $20 \mathrm{~m} \mathrm{~s}^{-1}$ from the low-to-strong to strong-to-severe wind speeds, a single linear relationship would not suffice for the entire distribution. It is expected that, based on the lower panel of Fig. 4, a similar type of incidence-angle dependence is required for nominal and severe wind speeds. There are insufficient points in the $U_{10}>20 \mathrm{~m} \mathrm{~s}^{-1}$ part of the distribution available (especially in the low incidence-angle part) to retrieve an incidence-angle relationship. Since there is a change in slope, and therefore the $\mathrm{VH}$ dependence on the ocean surface, one can not exclude that the incidence-angle dependence is different for the two regimes. Additional highwind hurricane images are required to probe the strong-tosevere wind-speed regime more thoroughly in a future effort.

The resulting $A$ and $B$ coefficients in the $7<U_{10}<$ $20 \mathrm{~m} \mathrm{~s}^{-1}$ regime are plotted and a second order polynomial (e.g., $A(\theta)=a_{0}+a_{1} \theta+a_{2} \theta^{2}$ ) was fitted through the points as depicted in Fig. 5 (top left and right panels respectively). The fitted parameters are provided in Table 2. Based on this parameterization, the measured VH signals can be globally made incidence angle independent by shifting all measurements to a single incidence angle, in this case 35 degrees, using the following equations:

$$
\begin{aligned}
\operatorname{VH}\left(\theta_{0}\right)= & \mathrm{VH}(\theta)+\Delta \mathrm{dB}\left(\theta, \theta_{0}\right) \\
\Delta \mathrm{dB}\left(\theta, \theta_{0}\right) & =\operatorname{VH}_{\mathrm{ECMWF}}\left(\theta_{0}\right)-\operatorname{VH}_{\mathrm{ECMWF}}(\theta) \\
& =\sum_{i=1}^{2} a_{i}\left(\theta_{0}^{i}-\theta^{i}\right)+\sum_{i=1}^{2} b_{i}\left(\theta_{0}^{i}-\theta^{i}\right) \cdot U_{10},
\end{aligned}
$$

where $\Delta \mathrm{dB}$ is calculated using Eq. (4), the fitted second order polynomial and $\theta_{0}=35$. Note that by describing the correction in this manner, it does not depend on the $a_{0}$ and $b_{0}$ values 


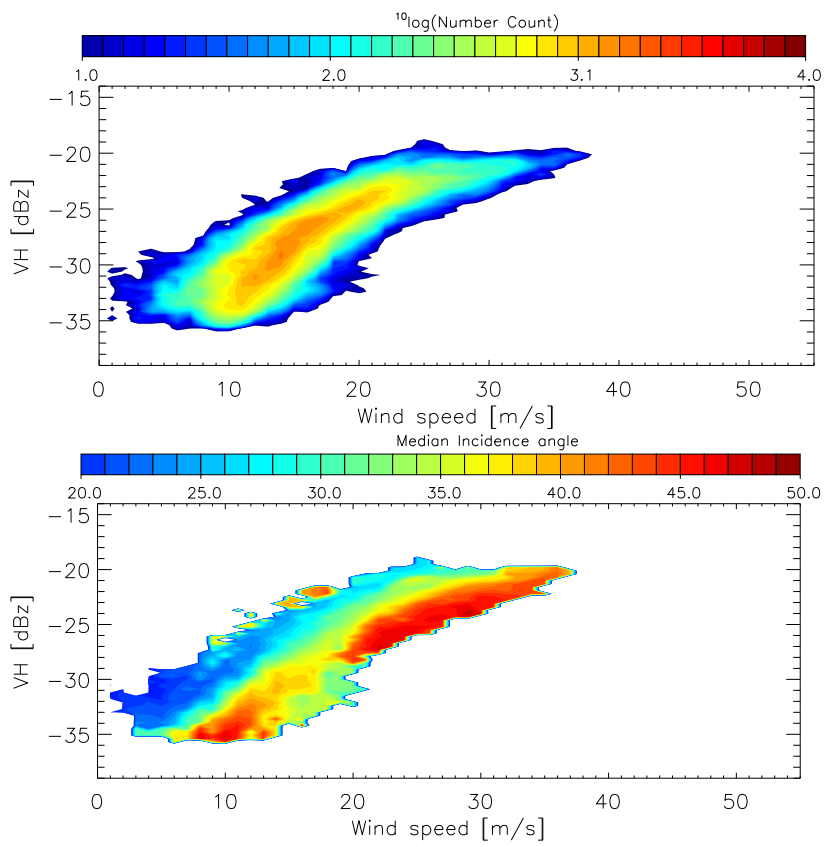

Fig. 4. The top panel shows the combined distribution of 19 hurricane images presenting their forecasted ECMWF velocities vs. collocated VH measurements. The distribution shows a tight relationship with a correlation of 0.85 . The distribution in the bottom panel depicts the median incidence angles, within $2 \mathrm{~ms}^{-1}$ by $2 \mathrm{~dB}$ bins, showing a clear incidence-angle relationship with the highest incidence angles at lowest backscatter values.

but only on the $\theta$ dependent coefficients. This reduces any bias between the ECMWF forecast wind speeds and the VH wind speeds for each incidence angle. As such, the resulting correlation between the ECMWF velocity and VH signal improves from 0.85 to 0.89 , which, by itself, is not significant. Also, the distance between the 0.2 and $0.8 \mathrm{VH}$ percentiles decrease to a minimum of $60 \%$ at $10 \mathrm{~m} \mathrm{~s}^{-1}$ up to $80 \%$ at $35 \mathrm{~m} \mathrm{~s}^{-1}$ compared to the original VH- $U_{10}$ (ECMWF) distribution. The decrease in distribution width is readily visible in the bottom panel of Fig. 5.

Both the SFMR and ECMWF comparisons show an incidence-angle dependence in contrast to what was found using the buoy data for wind speeds below $20 \mathrm{~m} \mathrm{~s}^{-1}$ (Vachon and Wolfe, 2011). Correcting the data for this dependence improves the description of the VH incidence-angle distribution and tightens the $U_{10}$ (ECMWF)-VH distribution. The joint wind speed and $\mathrm{VH}$ distribution is obtained through a combination of the matched sampled position and strengths of the wind speed. In this study, the wind speeds are not random with respect to their incidence angle, since hurricanes were targeted, which is the case for the comparison against buoys. As the data consists of a limited number (19) of hurricane images, it is conceivable that the coincident hurricane positions and strengths (distribution) (Fig. 6) within the RADARSAT-2 swath, as conceived by

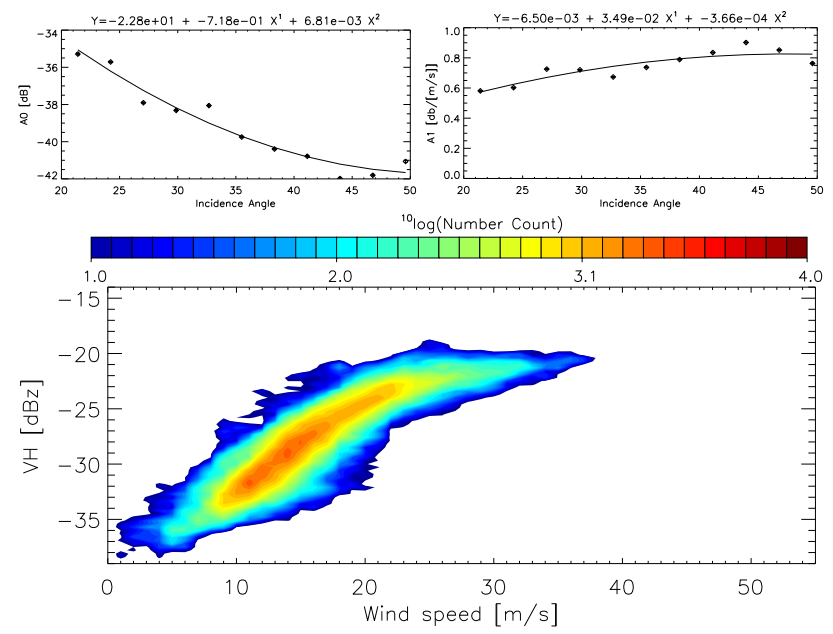

Fig. 5. $A$ (top left) and $B$ (top right) parameters from the linear regression fits vs. incidence angle. Overlaid are second order polynomials, described by the formula above each panel and Eq. (7). The bottom panel shows the incidence-angle corrected distribution (in comparison to Fig. 4). The distribution has a tight relationship with a correlation of 0.89 .

the different measurement systems introduces an apparent incidence-angle dependency. There is a relatively large number of hurricanes in the high incidence-angle regime (35$40^{\circ}$ ), where also the incidence-angle correction peaks (Fig. 5, upper panels). On the other hand, the incidence-angle dependence in the $U_{10}-\mathrm{VH}$ distribution (Fig. 4) lower panel shows a very similar behavior throughout the velocity range. In an additional test, performed to check for a potentially induced incidence-angle dependence, the $\mathrm{VH}-U_{10}$ (ECMWF) distribution was tested using a bootstrap technique. In this test, 10 thousand sample distributions were created between 7 and $20 \mathrm{~m} \mathrm{~s}^{-1}$, each consisting of 19 randomly drawn hurricane images using simple random sampling with replacement (i.e., an individual sample can consist of a single hurricane more than once). The incidence-angle relationship $\left(a_{i}\right.$ and $b_{i}$; Eq. 4) coefficients where determined for each of the samples and the moments for each of the coefficients were calculated. For all coefficients, the median and mean of the distribution where within $7 \%$ of the values derived in Table 2 . The individual parameters show a normal distribution (small skewness and kurtosis) with no additional secondary peaks, a potential indicator of one or more statistical outliers or a sample induced parameterization within the 19 hurricanes. The test indicates that the retrieved incidence-angle dependence is a well-defined feature of the hurricane data set; it does not necessarily mean the dependency is actually caused by the hurricane data set. As such additional data is required to ensure that the retrieved incidence-angle dependence is due to a physical process or an offset introduced by the sampling of hurricanes within the study. 
Table 2. Fitted parameters for the retrieved functions A and B (Eq. 7).

\begin{tabular}{llll}
\hline & $c_{0}$ & $c_{1}$ & $c_{2}$ \\
\hline $\mathrm{A}$ & -22.8 & $-7.18 \times 10^{-1}$ & $6.81 \times 10^{-3}$ \\
$\mathrm{~B}$ & $-6.50 \times 10^{-3}$ & $3.49 \times 10^{-2}$ & $-3.66 \times 10^{-4}$ \\
\hline
\end{tabular}

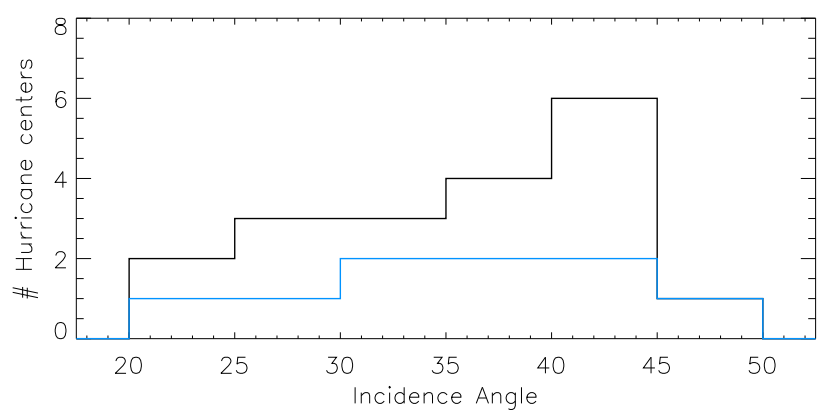

Fig. 6. Histogram of the hurricane center position with respect to the measured incidence angle for all hurricanes used in the ECMWF analysis (black line) and the SFMR analysis (blue line).

The retrieved incidence-angle dependence relationship is used only when using ECMWF forecast winds below $20 \mathrm{~m} \mathrm{~s}^{-1}$ because it was observed as a well-defined feature of the ECMWF-VH distribution. Any incidence-angle dependence in the wind speed above $20 \mathrm{~m} \mathrm{~s}^{-1}$, or when utilizing literature relationships (e.g., Vachon and Wolfe, 2011), is ignored and left for future work.

\subsubsection{Azimuthal angle dependence}

The VH data can subsequently be checked for a winddirection dependence. In Fig. 7, the data is binned with respect to the wind direction and wind speed. The color scale shows the median value of the measured VH (top panel) within each bin. It is observed in the plot that the $\mathrm{VH}$ versus wind speed shows no dependence to the winddirection angles, similar to what has been observed by Zhang and Perrie (2011) and Vachon and Wolfe (2011) in the $<20 \mathrm{~m} \mathrm{~s}^{-1}$ regime. The same observation is hereby also found/confirmed in the strong-to-severe $\left(>20 \mathrm{~m} \mathrm{~s}^{-1}\right)$ windspeed regime. In contrast to the earlier cited papers and this work, cross-polarization data from L-band radar systems (1$2 \mathrm{GHz}$ ) do show a wind-direction dependence (Yueh et al., 2010). The solid contour lines shown in Fig. 7 (top panel) depicts the $\mathrm{VH}$ cross-polarization signal variation derived in the L-band, which is much larger than any variations depicted by the colored contours. It is unknown why L-band exhibits a dependence on wind direction and C-band does not for cross-polarized data. For comparison, the center panel shows the median VV signal collocated with the VH measurements in the top panel. The VV signals are well described by the CMOD5.N equation $\left[\mathrm{VV}=B_{0} \cdot\left(1+B_{1} \cos (\phi)+B_{2} \cos \right.\right.$
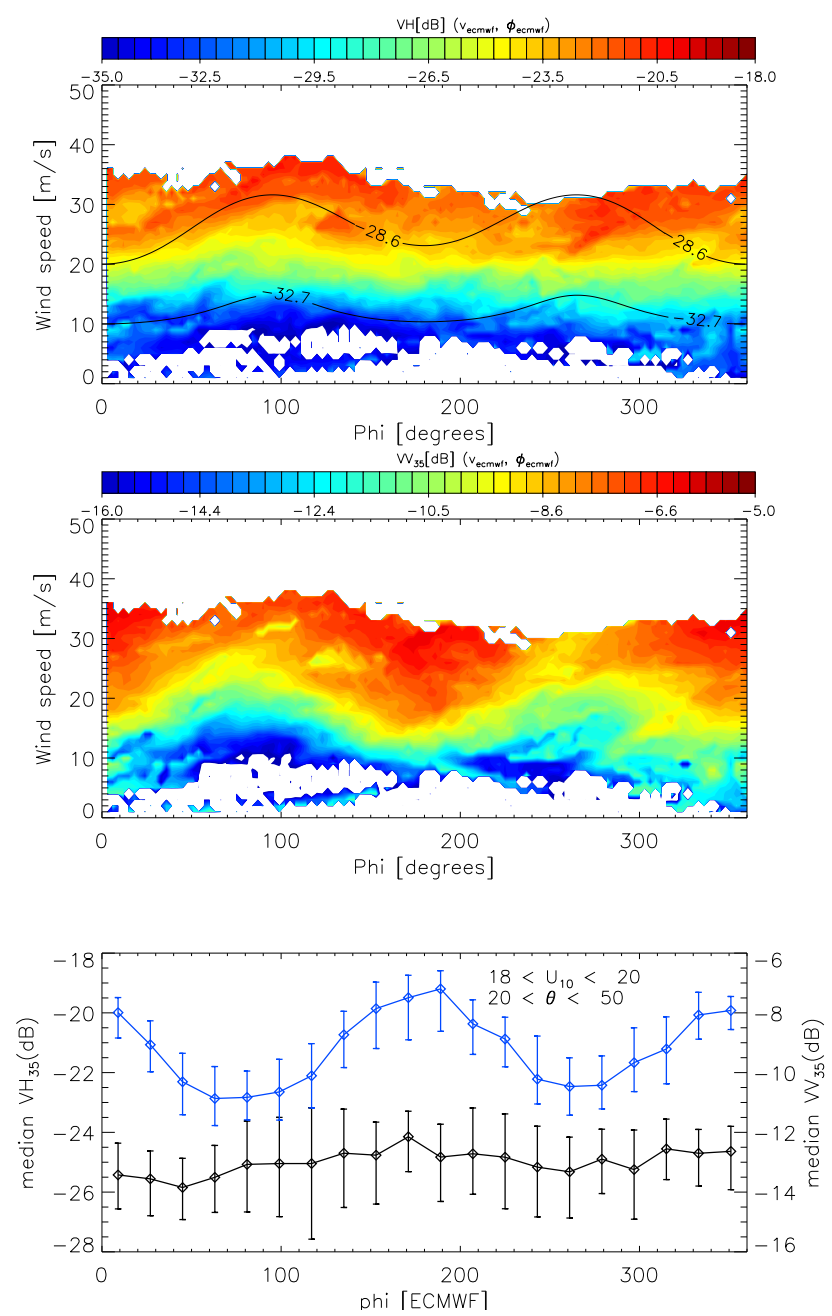

Fig. 7. Joint distributions of the median signal strength versus ECMWF wind velocities and the wind-direction angle for the combined 19 hurricane images. The color scale depicts the median incidence-angle corrected $\mathrm{VH}$ or $\mathrm{VV}$ at each position. In the top panel the wind-direction dependence of the VH signals vs. wind speed is shown, indicating the lack of wind-direction dependence in the $\mathrm{VH}$ channel. The solid black lines were derived from $\mathrm{L}$ band cross-polarization signals (Yueh et al., 2010), which do depend on the wind direction. The center panel shows the same plot but color coding the incidence angle corrected VV signals $\left(\mathrm{VV}_{35}\right)$. The $\mathrm{VV}_{35}$ signals show the well-described C-band wind-direction dependence with lower signals at cross-wind directions $\left(90^{\circ} \&\right.$ $\left.270^{\circ}\right)$ versus higher signals at up- and down-wind directions $\left(0^{\circ}\right.$ and $180^{\circ}$ ). Finally, in the bottom panel, both the median $\mathrm{VH}_{35}$ (black) and $\mathrm{VV}_{35}$ (blue) signals combining wind speeds between 18 and 20 $\mathrm{ms}^{-1}$ are shown.

$(2 \phi))]$, where $B_{0}$ depends on the local incidence angle and wind speed $\left(B_{0}=b_{00}(\theta) \cdot b_{01}\left(\theta, U_{10}\right)\right)$. The VV signals have been corrected for their incidence angle, in a very similar way as the $\mathrm{VH}$ signals in Eq. (7), by defining $\mathrm{VV}_{35}=\mathrm{VV} \cdot b_{00}$ $\left(\theta=35^{\circ}\right) / b_{00}(\theta)$. The $\mathrm{VV}_{35}$ measurements show the expected signal strength versus wind direction with high signals 
at 0 and 180 degrees and low signals at 90 and 270 degrees for all wind speeds between 10 and $30 \mathrm{~m} \mathrm{~s}^{-1}$. In an attempt to increase the signal-to-noise, all data between 18 and $20 \mathrm{~m} \mathrm{~s}^{-1}$ for all available incidence angles are combined and plotted against wind direction. The bottom panel shows the results for both the $\mathrm{VH}_{35}$ and $\mathrm{VV}_{35}$ relationships. The $\mathrm{VV}_{35}$ distribution is relatively tight (indicated by the error bars) in comparison the the $\mathrm{VH}_{35}$ distribution. In the $18-20 \mathrm{~m} \mathrm{~s}^{-1}$ range a good representation of the well-established harmonic dependency of the VV measurements is found, while the VH measurements showed, within the noise, no sign of a harmonic dependency. Based on the available data, the width of the $\mathrm{VH}_{35}$ distribution is dominated by its exponential relationship with respect to velocity, whereas the $\mathrm{VV}_{35}$ distribution is mostly dominated by its wind-direction relationship. The main conclusion from this analysis is that the VH signals show no wind-direction dependence within the available data; however, when taking into account the relatively wide distribution, a weak wind-direction dependence, especially with respect to the VV signal dependence, can not be excluded.

The apparent lack of dependence seen in the C-band cross polarization makes it a more robust wavelength for absolute wind-speed retrievals using a single observation only. It does require additional $\mathrm{VV}$ or $\mathrm{HH}$ measurements to retrieve both direction and wind speed.

\section{VH-GMF for strong-to-severe wind speeds}

Based on the various data sources it is evident that there are two wind regimes that exhibit a change in slope around $20 \mathrm{~m} \mathrm{~s}^{-1}$. As such, it is possible to construct GMF models/relationships from both the ECMWF winds and the SFMR winds:

1. ECMWF winds collocated with RADARSAT-2 VH data results in a well-defined distribution between 7 and $37 \mathrm{~ms}^{-1}$. In Fig. 8, the ECMWF winds vs. $\mathrm{VH}[\mathrm{dB}]$ data distribution (represented by the grayscale contours) reveals a distinct trend/dependence in the low-to-strong regime (dashed-blue line) where we observe a much steeper slope when compared to the strong-to-severe (solid blue line) wind-speed regime. The two linear relationships $\left(U_{10}-\mathrm{VH}[\mathrm{dB}]\right)$ cross at approximately $20 \mathrm{~m} \mathrm{~s}^{-1}$. For the low-to-strong wind-speed regime an incidence-angle dependence has been retrieved.

2. In Fig. 8, the distribution of the SFMR wind speed vs. the VH data shows a very similar pattern (depicted by the black contour lines and the associated linear fit is the red solid line) compared to the ECMWF distribution in the strong-to-severe wind-speed regime. The lower part of the distribution is incomplete in the $U_{10}<20 \mathrm{~m} \mathrm{~s}^{-1}$ and $\mathrm{VH}<30 \mathrm{~dB}$ region. The SFMR

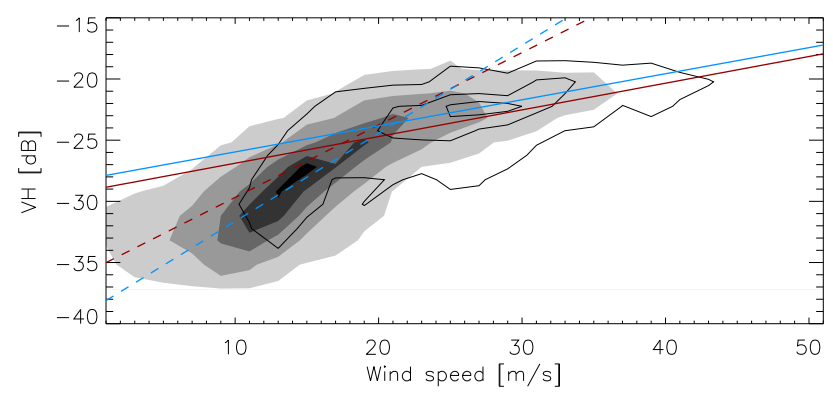

Fig. 8. The above graph combines the ECMWF-VH (represented by the grayscale contours) and the SFMR-VH distributions (represented by the contoured lines). The four lines overlaid depict the four linear fits presented in Table 3 that define the VH-GMF. The dashed red line is the Vachon and Wolfe (2011) linear fit, the two blue lines are the linear fits based on the ECMWF data and the solid red line the linear fit based on the SFMR data.

retrieved velocity is a superior product since it has been calibrated using drop sondes during the flights at strong and severe winds. In the low-to-strong windspeed regime additional data is available by assuming the validity of the wind-speed relationship from Vachon and Wolfe (2011) or Zhang et al. (2011) which is based on collocated VH data with in situ buoy measurements.

The four relevant linear relationships are provided in Table 3 and Fig. 8, where the low-to-strong wind-speed relationship based on the ECMWF data has been corrected for incidence angle. The main difference in the two strongto-severe regime parameterizations is an offset of $1 \mathrm{~dB}$ (see Fig. 8 and Table 3). This results in an approximate difference of 3.7 to $4.8 \mathrm{~m} \mathrm{~s}^{-1}$, between $\mathrm{VH}$ : -21 and $-30 \mathrm{~dB}$, respectively, for which the retrieved wind speeds based on SFMR data exceeds the ECMWF-based retrieval. The apparent transition between the low-to-strong wind speeds and the strongto-severe wind speeds has to be taken into account in the $\mathrm{VH}-$ GMF. Two potential methods are considered here to ensure this:

- Calculate the wind speed using the relationship in the low-to-strong wind speeds and strong-to-severe wind speeds and calculate the local maximum of the two functions. This ensures that there is an easy transition from one to the other relationship, but the procedure will result in a sharp edge at the transition point.

- Create a continuous function by combining the two relationships in the following way $U_{10}=\left(\left(U_{10}[\mathrm{LS}]\right)^{p}+\right.$ $\left.\left(U_{10}[\mathrm{SE}]\right)^{p}\right)^{1 / p}$, where LS stands for low-to-strong relationship, SE for the strong-to-severe relationship and $p$ is equal to 10 .

The high value of $p$ ensures that the combined velocity is weighted towards the largest of the two function values. 
Table 3. The two possible VH-GMF parameterizations based on the Vachon and Wolfe (2011) parameterization combined with the SFMR data fit (left side) and on the ECMWF model data (right side). The ECMWF fit in the low-to-strong wind speeds is corrected for its incidence angle.

\begin{tabular}{lll}
\hline & Vachon + SFMR & ECMWF \\
\hline Low-to-strong & $\mathrm{VH}[\mathrm{dB}]=0.59 U_{10}-35.60$ & $\mathrm{VH}_{35}[\mathrm{~dB}]=0.76 U_{10}-39.53$ \\
Strong-to-severe & $\mathrm{VH}[\mathrm{dB}]=0.218 U_{10}-29.07$ & $\mathrm{VH}[\mathrm{dB}]=0.213 U_{10}-28.09$ \\
\hline
\end{tabular}

In the transition regime both functions have non-negligible weights, resulting in a smooth transition with a continuous derivative.

In Fig. 9, the different relationships of the wind speed are compared to the $\mathrm{VH}$ measurements for Hurricane Earl. In the top left panel, the Vachon and Wolfe (2011) parameterization is adopted. This results in wind speeds lower than $30 \mathrm{~m} \mathrm{~s}^{-1}$, which indeed indicates that this relationship does not do a good job of defining the high wind speeds found in hurricanes. The wind speed in the top right panel shows the retrieval based on the ECMWF fits. The bottom left panel uses the SFMR data for the strong-to-severe winds and the Vachon and Wolfe (2011) relationship for the low-to-strong wind speeds. In the bottom right panel, the SFMR velocities along a flight leg are plotted; the transect itself is shown as the black line in the top left panel. Overlaid are the collocated retrieved wind speeds from the three retrievals and the VV-GMF. The higher wind speeds in the bottom left panel vs. the top right panel in Fig. 9 show the influence of the offset in the VH-GMF when using the SFMR + Vachon and Wolfe (2011) fits versus the ECMWF fits. It also provides a good indication of the uncertainties involved when using the cross-polarization signals to retrieve the wind speed. Since the SFMR instrument is specifically calibrated for hurricane winds, the Vachon and Wolfe (2011) parameterization is based on in situ measurements and the maximum velocity on which the ECMWF fit is based is only $37 \mathrm{~ms}^{-1}$, the proposed VH-GMF is based on the combination of the Vachon and Wolfe (2011) and SFMR fit (Table 3). The strong sensitivity of the retrieved wind speed to the exact linear fits and the need to assess an incidence-angle dependence for the strong to severe winds requires additional data not available at this point. Future work should take into account a large number of additional hurricane (and typhoon) images with collocated SFMR measurements, both in time and space. The addition of new cross-polarization channels to the NOAA aircraft instrument should, together with satellite data, assist in a more accurate definition of a future VH-GMF. Nonetheless, with the currently available data, one can conclude that cross-polarization signals from satellites will enable the retrieval of strong-to-severe wind speeds where $\mathrm{VV}(/ \mathrm{HH})$ data has saturated.

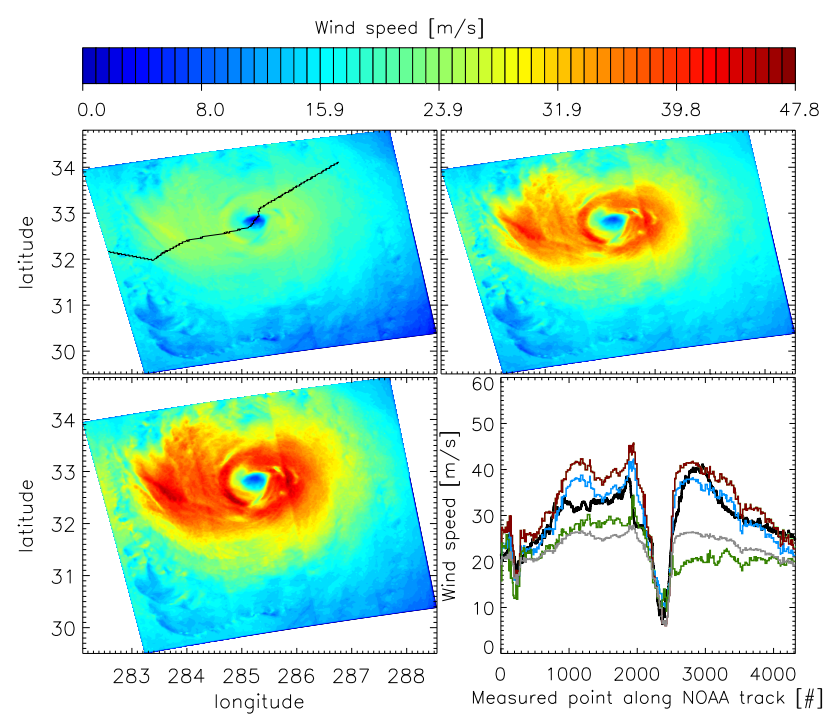

Fig. 9. Top left, the wind speed using the Vachon and Wolfe (2011) relationship. The solid black line depicts the SFMR flight track through the hurricane. Top right, the wind speed retrieved using the two ECMWF fits. The bottom left panel shows the results using the Vachon and Wolfe (2011) and SFMR fit. In the bottom right figure the NOAA track through the hurricane is plotted with the SFMR retrievals (black), the Vachon and Wolfe (2011) results (green), VVGMF (light grey), the SFMR + Vachon and Wolfe (2011) fits (red) and ECMWF fits (blue).

\section{Potential of near-real-time assessment of the NOAA best track estimates}

In the previous sections, a VH-GMF was presented showing a linear relationship of $\mathrm{VH}[\mathrm{dB}]$ with respect to the local wind speed. Since the amount of data available is not yet sufficient to retrieve a unique relationship (with low error estimates) for the entire range of potential wind speeds, it is important to validate the retrieved VH-GMF. The correspondence between the SFMR data and VH-GMF retrievals (Fig. 9) is, in part, due to the input data, as the hurricane image was used in both the ECMWF and SFMR fitting. Even though the bootstrap tests show that the resulting fits do not depend or change due to a single hurricane image, the comparison is not independent. Furthermore, the simple relationship found in this and previous studies suggest the potential use of the VH measurements for a near-real-time wind speed assessment in the case of hurricanes and typhoons, thereby enabling hurricane 
prediction centers to improve their forecasts and potential damage assessments. In this section, the VH measurements are compared to the Tropical Cyclone Best-Track Information product from the NHC GIS Archive ${ }^{3}$. This Best Track is a subjectively smoothed representation of the tropical cyclone's location and intensity. The intensity is described as its maximum 1 min sustained surface wind speed and minimum sea-level pressure at $6 \mathrm{~h}$ intervals over its lifetime. The track and intensity values are determined as a post storm assessment of all available data. The track data itself is intended for regional-scale analysis and will not show the hurricane's erratic motions over its lifetime (see website for more detailed information on the product). The VH images and their retrieved velocities are independent of the NOAA best track assessment data, but also describe the hurricane in a very different way. The VH-GMF results are based on a high-spatialresolution snapshot, whereas the NOAA best track is a single intensity value of maximum sustained wind depending on time, and when comparing them, the variability has to be treated in a different way. For the VH-GMF, only the tail of the image distribution is important since it describes the highest wind velocities. In the case of the 1-minute maximum sustained winds the most important issue is its stability in time, since this describes how stable the wind-speed estimate is at the time of the RADARSAT-2 overpass. For each hurricane image, the NOAA best track intensity is estimated by interpolating the maximum velocity to the satellite overpass time and the associated error is defined as the standard deviation of the five closest $6 \mathrm{~h}$ points of the NOAA track. This means that the more variable the hurricane is in its lifetime (e.g., it is increasing or decreasing in strength within a $24 \mathrm{~h}$ window), the larger the local error bar. For the retrieved VHGMF velocities, a land-sea mask is applied to disregard high $\mathrm{VH}$ values due to land return. If one would subsequently take the highest wind speed in the image, the value could depend on high returns from non-sea-surface targets (e.g., coastlines or small islands that were not removed by the land-sea mask operation, ships or an occasional single high noise pixel). Instead of comparing the maximum retrieved wind speed, the 0.995 and 0.9995 percentile wind-speed values are retrieved with the center defined as its mean velocity value to ensure a robust retrieved value. These values are specific for the used swath of the RADARSAT-2 instrument and could change for other cross-polarization instruments. The top panel of Fig. 10 has a plot that indicates which hurricanes have SFMR data (blue dots) and those that do not have SFMR data (red dots). The linear fit (solid line) was estimated taking into account both the variability (error) estimates in $x$ and $y$ and has a correlation of 0.83 and a slope of 1.39 . The difference in slope between the VH-GMF and the $1: 1$ line could be caused by a number of issues including the lack of an incidence-angle correction, the difference in the "meaning" of the velocity value (high spatial resolution versus an averaged time signal)
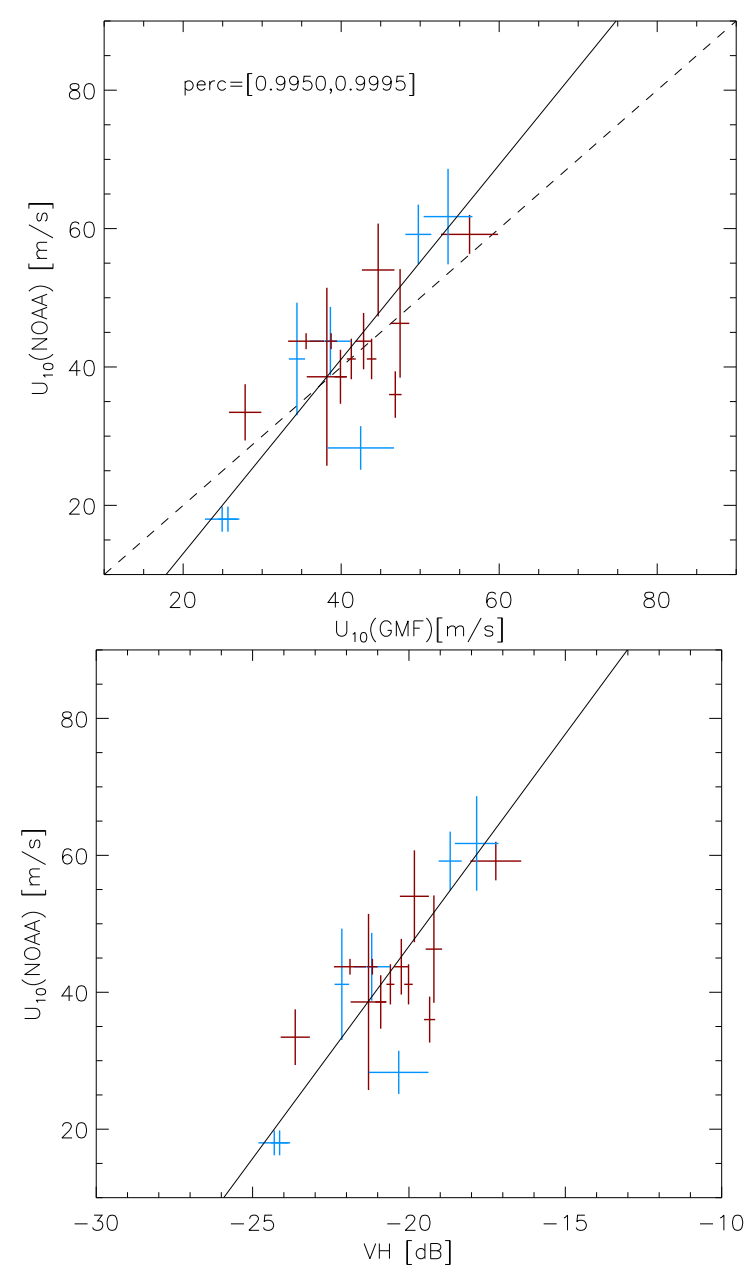

Fig. 10. Comparison of the maximum 1 min sustained surface wind speed best track estimates versus the averaged sum of the VH-GMF retrieved velocities of the 0.995 and 0.9995 percentiles for each hurricane image used in this study (top panel). The error estimates in the $x$ direction show the two percentile values and represent the variability close to the eye within the image, the $y$ direction error bar shows the standard deviation within a $24 \mathrm{~h}$ window around the RADARSAT- 2 overpass time. The red color indicates those hurricanes which did not have collocated SFMR flights around the time of the satellite overpass, the remaining (blue) points indicate the images which were used to create the SFMR-VH distribution. The bottom panel shows the same figure but in this case the relationship of the direct $\mathrm{VH}$ values versus maximum 1 min sustained surface wind speed.

and finally the use of percentile values lower than 1.0. Since the VH-GMF at these wind speeds is described using a linear relationship in the strong-to-severe wind regime, one can also directly plot the $\mathrm{VH}(0.995,0.9995)$ percentile values against the NOAA best estimate as is shown in the bottom panel of Fig. 10. As expected, the plot indicates a linear relationship with a correlation factor of 0.83 ,

\footnotetext{
${ }^{3}$ http://www.nhc.noaa.gov/gis/
} 
$U_{10}(\mathrm{NOAA})=170.69+6.20\left(\frac{\mathrm{VH}[0.995]+\mathrm{VH}[0.9995]}{2}\right)$.

The value in square brackets defines the cross-polarization percentile value to be used from a single RADARSAT- 2 image which has been land masked and incorporates the eye of the hurricane to ensure that the strongest wind speeds are within the image. The width of the distribution can be decreased when more hurricane SFMR data is available in order to define the incidence-angle dependence in the strong-tosevere wind-speed regime and by adding more points to this plot, i.e., images of typhoons or hurricanes. Note that this is not the same relationship as was defined earlier (Eq. 3), which was defined using all available data instead of being based on statistics of the extreme values. The comparisons between the ECMWF data, SFMR and best-track wind speeds vs. the measured VH data sets are independent and bring forward two important conclusions:

1. The cross-polarization radar return in C-band increases exponentially with respect to wind velocity (linear $U_{10}-\mathrm{VH}[\mathrm{dB}]$ ) as has been found by three independent wind-speed data records, but now up to $60 \mathrm{~ms}^{-1}$.

2. A near-real-time assessment of maximum sustained wind speed is possible using cross-polarization measurements. This will be extremely useful for hurricane forecast warnings and hurricane model run initialization.

\section{Conclusions}

In this work, cross-polarized $(\mathrm{VH})$ backscatter signals from RADARSAT-2 C-band SAR imagery acquired during severe wind-speed (hurricane) events were compared to the collocated and time co-incident SFMR wind measurements acquired by NOAA's hurricane-hunter aircraft. From this data set, a relationship for wind-speed retrieval using $\mathrm{VH}$ polarization backscatter for strong-to-severe wind speeds (i.e., $20 \mathrm{~m} \mathrm{~s}^{-1}<U_{10}<45 \mathrm{~m} \mathrm{~s}^{-1}$ ) was derived. Within this wind-speed regime, the cross-polarized data showed no distinguishable loss of sensitivity and, as such, cross-polarized signals are a good candidate for the retrieval of severe wind speeds from satellite instruments. The $\mathrm{VH}$ signals increase exponentially with wind speed and are described as linear relationships of $U_{10} \mathrm{vs}$. $\mathrm{VH}[\mathrm{dB}]$.

The upper limit of $45 \mathrm{~ms}^{-1}$ is set by the currently available collocated data. The validity of the retrieved linear relationship $\left(U_{10}-\mathrm{VH}[\mathrm{dB}]\right)$ has been evaluated by comparing the cross-polarized data to two additional independent windspeed data sets (i.e., the short-range ECMWF model forecast and the NOAA best estimate 1-minute maximum sustained winds from their GIS database). Comparing these data sets results in the following conclusions:
- The VH backscatter relationship to wind speed shows a different behavior in the low-to-strong wind-speed regime $\left(U_{10}<20 \mathrm{~m} \mathrm{~s}^{-1}\right)$ compared to the strong-tosevere wind-speed regime $\left(U_{10}>20 \mathrm{~m} \mathrm{~s}^{-1}\right)$. The lowto-strong wind-speed regime is described by the relationship found by Vachon and Wolfe (2011) and the strong-to-severe wind regime by the relationship retrieved here (Eq. 3).

- The VH backscatter shows a modest incidence-angle dependence. A correction for this dependence is only feasible for wind speeds up to $20 \mathrm{~m} \mathrm{~s}^{-1}$ due to the low amount of severe wind-speed data. Additional data is needed to determine the incidence-angle dependence in the strong-to-severe wind regime and determine its origin (geophysical or calibration).

- Within the available VH backscatter signals no winddirection dependence can be determined. At maximum the wind-direction dependence is small in comparison to the wind-speed dependence, especially in comparison to the VV backscatter relationships. This means that ocean wind speeds can be directly retrieved from a VH channel in the C-band. For an operational wind product, three additional $\mathrm{VV}$ or $\mathrm{HH}$ beams are required to retrieve the wind speed and direction up to $24 \mathrm{~m} \mathrm{~s}^{-1}$. Combining the information from both the VV and $\mathrm{VH}$ signals should enable the calculation of wind direction for larger wind speeds. In the case of hurricane force winds, the knowledge of wind speeds is more important than the wind direction, as the former denotes the class and devastation of the hurricane. In those cases the wind direction can be defined by the general flow pattern (e.g., in the case of hurricanes and typhoons the wind rotates around the eye).

- There is a strong correlation between the highest VH measurements within a hurricane SAR image and the 1-minute maximum sustained wind speeds from the NOAA best track product and can be described by a linear relationship $\left(U_{10}-\mathrm{VH}[\mathrm{dB}]\right)$. Since this relationship is only based on a combination of the most extreme VH measurements, it is different from the more general VH-GMF which is found by comparing all available SFMR collocated measurements.

- An operational satellite with a VH channel will be able to retrieve, in near-real-time, the 1-minute maximum sustained wind speed from a hurricane or typhoon, as well as be able to make an assessment of the spatial wind-speed distribution. Up to the launch of the MetOP-SG satellites this may be performed by the RADARSAT-2 satellite, as long as this is possible within its measurement schedule and science mandate. 
Acknowledgements. This work has been carried out within the context of the EUMETSAT Ocean and Sea Ice Satellite Application Facility (OSI-SAF). We much acknowledge the availability of the RADARSAT-2 VH backcatter data through the Canadian Space Agency's Hurricane Watch program. The SFMR data used was provided by the NOAA Hurricane Research Division (http://www.aoml.noaa.gov/hrd/data_sub/sfmr.html). The NOAA best track data are provided by the NHC GIS Data and Products website (http://www.nhc.noaa.gov/gis/), the HWIND model is created by the NOAA Hurricane Research Division of AOML and was provided through http://www.aoml.noaa.gov/hrd/data_sub/wind.html.

Edited by: J. Joiner

\section{References}

Bourassa, M. A., Stoffelen, A., Bonekamp, H., Chang, P., Chelton, D. B., Courtney, J., Edson, R., Figa, J., He, Y., Hersbach, H., Hilburn, K., Jelenak, Z., Kelly, K. A., Knabb, R., Lee, T., Lindstrom, E. J., Liu, W. T., Long, D. G., Perrie, W., Portabella, M., Powell, M., Rodriguez, E., Smith, D. K., Swail, V., and Wentz, F. J.: Remotely sensed winds and wind stresses for marine forecasting and ocean modeling, in: Proceedings of OceanObs'09: Sustained Ocean Observations and Information for Society, 21-25 September 2009, Vol. 2, edited by: Hall, J., Harrison, D. E., and Stammer, D., Venice, Italy, doi:10.5270/OceanObs09.cwp.08, 2009.

Belmonte Rivas, M., Stoffelen, A., and van Zadelhoff, G.-J.: The Benefit of $\mathrm{HH}$ and VV Polarizations in Retrieving Extreme Wind Speeds for an ASCAT-Type Scatterometer, IEEE T. Geosci. Remote Sens., 99, 1-8, doi:10.1109/TGRS.2013.2280876, 2013.

Horstmann, J. and Koch, W.: Measurement of ocean surface winds using synthetic aperture radars, IEEE J. Ocean. Eng., 30, 508515, doi:10.1109/JOE.2005.857514, 2005.

Horstmann, J., Wackerman, C., Falchetti, S., and Maresca, S.: Tropical cyclone winds retrieved from synthetic aperture radar, Oceanography, 26, 46-57, doi:10.5670/oceanog.2013.30, 2013.

Hwang, P. A., Zhang, B., and Perrie, W.: Depolarized radar return for breaking wave measurement and hurricane wind retrieval, Geophys. Res. Lett., 37, L01604, doi:10.1029/2009GL041780, 2010a.

Hwang, P. A., Zhang, B., Toporkov, J. V., and Perrie, W.: Comparison of composite Bragg theory and quad-polarization radar backscatter from RADARSAT-2: with applications to wave breaking and high wind retrieval, J. Geophys. Res., 115, C08019, doi:10.1029/2009JC005995, 2010b.

Lehner, S., Horstmann, J., Koch, W., and Rosenthal, W.: Mesoscale wind measurements using recalibrated ERS SAR images, J. Geophys. Res.-Oceans, 103, 7847-7856, doi:10.1029/97JC02726, 1998.

Portabella, M., Stoffelen, A., and Johannessen, J. A.: Toward an optimal inversion method for synthetic aperture radar wind retrieval, J. Geophys. Res.-Ocean, 107, 1.1-1.13, doi:10.1029/2001JC000925, 2002.
Powell, M. D., Houston, S. H., Amat, L. R., and MorisseauLeroy, N.: The HRD real-time hurricane wind analysis system, J. Wind Eng. Ind. Aerod., 77-78, 53-64, doi:10.1016/S01676105(98)00131-7, 1998.

Romeiser, R., Alpers, W., and Wismann, V.: An improved composite surface model for the radar backscattering cross section of the ocean surface: 1 . Theory of the model and optimization/validation by scatterometer data, J. Geophys. Res.-Oceans, 102, 25237-25250, doi:10.1029/97JC00190, 1997.

Slade, B.: RadarSAT-2 product description, Tech. rep., MacDonald, Dettwiler and Associates Ltd., available at: http: //gs.mdacorporation.com/SatelliteData/Radarsat2/Products.aspx (last access: August 2013), 2011.

Stoffelen, A. and Portabella, M.: On Bayesian scatterometer wind inversion, IEEE T. Geosci. Remote, 44, 1523-1533, doi:10.1109/TGRS.2005.862502, 2006.

Uhlhorn, E. W., Black, P. G., Franklin, J. L., Goodberlet, M., Carswell, J., and Goldstein, A. S.: Hurricane surface wind measurements from an operational stepped frequency microwave radiometer, Mon. Weather Rev., 135, 3070-3085, doi:10.1175/MWR3454.1, 2007.

Vachon, P. W. and Wolfe, J.: C-band cross-polarization wind speed retrieval, IEEE Geosci. Remote S., 8, 456-459, doi:10.1109/LGRS.2010.2085417, 2011.

Verhoef, A., Portabella, M., Stoffelen, A., and Hersbach, H.: CMOD5.n - the CMOD5 GMF for neutral winds, Tech. rep., Document external project: 2008, SAF/OSI/CDOP/KNMI/TEC/TN/165, EUMETSAT, Darmstadt, 2008.

Vogelzang, J. and Stoffelen, A.: Scatterometer wind vector products for application in meteorology and oceanography, J. Sea Res., 74, 16-25, doi:10.1016/j.seares.2012.05.002, 2012.

Vogelzang, J., Stoffelen, A., Verhoef, A., and Figa-Saldaña, J.: On the quality of high-resolution scatterometer winds, J. Geophys. Res.-Oceans, 116, C10033, doi:10.1029/2010JC006640, 2011.

Voronovich, A. and Zavorotny, V.: Depolarization of microwave backscattering from a rough sea surface: modeling with small-slope approximation, in: Geoscience and Remote Sensing Symposium (IGARSS), 2033-2036, doi:10.1109/IGARSS.2011.6049530, 2011.

Wackerman, C., Rufenach, C., Shuchman, R., Johannessen, J., and Davidson, K.: Wind vector retrieval using ERS-1 synthetic aperture radar imagery, IEEE T. Geosci. Remote, 34, 1343-1352, doi:10.1109/36.544558, 1996.

Yueh, S., Dinardo, S., Fore, A., and Li, F.: Passive and active L-band microwave observations and modeling of ocean surface winds, IEEE T. Geosci. Remote, 48, 3087-3100, doi:10.1109/TGRS.2010.2045002, 2010.

Zhang, B. and Perrie, W.: Cross-polarized synthetic aperture radar: a new potential measurement technique for hurricanes, B. Am. Meteorol. Soc., 93, 531-541, doi:10.1175/BAMS-D-11$00001.1,2011$.

Zhang, B., Perrie, W., and He, Y.: Wind speed retrieval from RADARSAT-2 quad-polarization images using a new polarization ratio model, J. Geophys. Res., 116, C08008, doi:10.1029/2010JC006522, 2011. 